\title{
HEGEMONIA E IMPERIALISMO NA CONTEMPORANEIDADE: CONCEITOS COMPARADOS EM GIOVANNI ARRIGHI E DAVID HARVEY
}

\author{
Rodolfo Vaz \\ Demétrio Gaspari Cirne de Toledo
}

\begin{abstract}
RESUMO
O presente estudo coloca em evidência dois conceitos da tradição marxista, hegemonia e imperialismo, cada qual referenciado em um autor. Giovanni Arrighi e David Harvey seguem esses conceitos para sustentar teorias e opiniões divergentes a respeito da dinâmica e perspectiva histórica do capitalismo contemporâneo. Entender a construção do seu pensamento, e como travaram uma interessante discussão sobre o tema em questão, é a missão desta investigação.
\end{abstract}

Palavras-chave: capitalismo, hegemonia, imperialismo, acumulação, dominação.

\begin{abstract}
The present study highlights two concepts of the Marxist tradition, hegemony and imperialism, each of which is referenced in one author. Giovanni Arrighi and David Harvey follow these concepts to support divergent theories and opinions about the dynamics and historical perspective of contemporary capitalism. Understand the construction of your thinking, and how they engaged in an interesting discussion on the subject in question, is the mission of this investigation.
\end{abstract}

Key words: capitalism, hegemony, imperialism, accumulation, domination. 


\section{Introdução}

A tradição Marxista vem tentando produzir abordagens teóricas que deem conta das profundas metamorfoses dentro do modo de produção capitalista. Isso implica em realizar uma análise histórico concreta, dos ciclos de acumulação e produção de mais-valor que se estabeleceram a partir da Segunda revolução Industrial, cuja consequência mais evidente é a formação de novas ondas de colonização em África e Ásia, e que assumiram uma dinâmica aprofundada posteriormente (POSTONE, 2015).

A subsequente expansão do capital em escala global, analisada de forma profunda por Lenin (1987) e Rosa Luxemburgo (1984), apontava um projeto de dominação em escala intercontinental, e desafiava os pensadores a identificar a gênese da acumulação capitalista e compreender o papel do Estado como agente político central na organização desse processo.

O economista político italiano Giovanni Arrighi (2013) e o geógrafo britânico David Harvey (2006) são Referências Bibliográficas no assunto e elaboraram teorias distintas a respeito do desenvolvimento do capitalismo contemporâneo, mas guardam também muitas similaridades. Uma delas se refere ao entendimento que a crise econômica da década de 1970 inaugurou uma fase de declínio econômico do capitalismo internacional e de decadência da hegemonia estadunidense. Contudo, suas divergências começaram na interpretação da dinâmica desta crise, e consequentemente as análises se desdobraram de acordo com os critérios e conceitos que cada um assumiu para encarar o debate.

O próprio Arrighi, na introdução de O Longo Século XX, trata de delimitar a ênfase de Harvey sobre a crise de 1970 e notar que

As indagações que geraram este estudo são semelhantes às de Harvey. Mas as respostas são buscadas numa investigação das tendências atuais à luz de padrões de repetição e evolução que abarcam todo o curso do capitalismo histórico como sistema mundial. Uma vez que ampliemos dessa maneira o horizonte espaço-temporal de nossas observações e conjecturas teóricas, tendências que pareciam inéditas e imprevisíveis começam a afigurar-se familiares. (ARRIGHI, 2013, p.4)

Numa primeira aproximação já temos Arrighi elencando alguns dos pressupostos teóricos chaves na sua análise, e é nesse sentido que nos propomos a fazer a presente investigação: assinalar as ferramentas teóricas dos dois autores ao redor de dois conceitos centrais que são pontos de partida em suas concepções. $\mathrm{O}$ italiano se apoia no conceito de hegemonia, enquanto o britânico traça sua teoria a partir do conceito de imperialismo.

Examinaremos os principais aspectos da teoria de ambos e apontaremos, na sequência, as principais críticas conjuradas de um a outro autor. Com esse método, ficarão mais evidentes as divergências, concretamente falando, e nos aproximaremos mais do 
entendimento da construção lógico-argumentativa de cada pensador.

\section{Giovanni Arrighi e o conceito de Hegemonia}

Hegemonia constitui a pedra fundamental na obra de Arrighi, pois é a principal ferramenta de uma definição mais ampla, a base da sua teoria dos ciclos de acumulação sistêmicos: os ciclos hegemônicos sistêmicos. Quer dizer, antes de ir direto à análise comparativa dos sucessivos ciclos de acumulação, o italiano faz um estudo sobre a gênese das hegemonias do capitalismo histórico, analisando os principais fatores que demarcam essa dinâmica.

$\mathrm{O}$ termo hegemonia tem origem na social-democracia russa no início do século $\mathrm{XX}$, e foi usado por Plekhanov, Axelrod e Lenin na discussão a respeito sobre o futuro papel dirigente do proletariado na revolução russa (ANDERSON, 1976). Lenin defendia uma noção hegemônica a ser desempenhada através da ditadura do proletariado, onde na luta política pelo poder de Estado caberia à classe operária liderar as forças proletárias e dos setores médios da sociedade (como o campesinato), buscando fazer prevalecer um Estado que imponha a defesa dos interesses da maioria da sociedade russa contra a minoria burguesa e aristocrática. Por todas as circunstâncias da Revolução Russa e da guerra civil que se seguiu pós-1917, essa hegemonia foi exercida prioritariamente através da força coercitiva.

Segundo Perry Anderson (1976), a adoção deste termo por Gramsci fez dele um novo conceito dentro do marxismo. Era notório que as complexidades estruturais capitalistas das nações ocidentais colocavam um problema para o desempenho da luta política proletária, mesmo Lenin reconhecia-o. As estruturas políticas atuavam de forma preventiva através das instituições para impedir a ascensão de formas de poder das classes trabalhadoras que pudesse pôr em risco sua dominação política.

Gramsci, então, estava preocupado em compreender a força e a complexidade da dominação burguesa na Europa Ocidental, e desenvolveu seu conceito de hegemonia com este objetivo. De modo geral, para ele hegemonia é o exercício de uma supremacia:

a supremacia de um grupo se manifesta de dois modos, como "domínio" e como "direção intelectual e moral". Um grupo social domina os grupos adversários, que visa a "liquidar" ou a submeter inclusive com a força armada, e dirige os grupos afins e aliados. Um grupo social pode e, aliás, deve ser dirigente já antes de conquistar o poder governamental (esta é uma das condições fundamentais inclusive para a própria conquista do poder); depois, quando exerce o poder e mesmo se o mantém fortemente nas mãos, torna-se dominante, mas deve continuar a ser também [dirigente]. ( GRAMSCI, 1971, p. 57-58, apud ARRIGHI, 2013, p.28)

Faz-se necessário considerar um aspecto relevante apontado por Anderson: 
A teoria da hegemonia de Gramsci possui também uma peculiaridade no seio desta tradição; ela não tinha apenas por base a sua participação pessoal nos conflitos políticos contemporâneos, mas também uma investigação comparativa da história europeia anterior extremamente íntima. (ANDERSON, 1976, p.105)

Partindo desta definição de Gramsci, Arrighi define:

O conceito de 'hegemonia mundial' aqui adotado, no entanto, refere-se especificamente à capacidade de um Estado exercer funções de liderança e governo sobre um sistema de nações soberanas. (...) Esse poder é algo maior e diferente da "dominação" pura e simples. É o poder associado à dominação, ampliada pelo exercício da "liderança intelectual e moral. (ARRIGHI, 2013, p.27)

Influenciado principalmente por Fernand Braudel, ele analisa as origens do sistema interestatal moderno e identifica a evolução estrutural do capitalismo histórico em ciclos de acumulação sistêmicos, alinhados aos ciclos hegemônicos. $\mathrm{O}$ entendimento de como ocorria a ascensão e a decadência hegemônica servia de suporte teórico para o entendimento da dinâmica da acumulação nestes mesmos ciclos. Resumidamente, ocorreram/ocorrem quatro ciclos: um ciclo hegemônico das cidades-estado italianas, do século XV até o fim do século XVI, depois um ciclo da hegemonia das Províncias Unidas (atual Holanda) até a maior parte do século XVIII, um ciclo hegemônico britânico até o início do século XX, e o ciclo hegemônico estadunidense até a contemporaneidade.

A configuração das nações modernas levou a que ocorresse uma forte disputa entre elas pela supremacia político-econômica. Todavia, essa disputa se dava também entre formas pré-capitalistas que persistiam e impediam a realização do desenvolvimento capitalista moderno. $\mathrm{O}$ capitalismo não teve uma expansão homogênea, e a economia mundial era uma multiplicidade de sistemas políticos. Às nações que ascendiam através da acumulação de capital cabia o papel de liderar intelectual e moralmente o sistema interestatal de forma ordenada, preservando as formas (anárquicas) de concorrência entre os Estados-nação. Arrighi denominou esse fenômeno como "anarquia ordenada".

Como a disputa interestatal prossegue, o início da decadência de uma hegemonia marca também a ocorrência do "caos sistêmico", uma situação marcada pela ausência de organização:

à medida que aumenta o caos sistêmico, a demanda de "ordem" (...) tende a se generalizar cada vez mais entre os governantes, os governados, ou ambos. Portanto, qualquer Estado ou grupo de Estados que esteja em condições de atender a essa demanda sistêmica de ordem tem a oportunidade de se tornar mundialmente hegemônico. (ARRIGHI, 2013, p. 30)

"Anarquia ordenada" e "caos sistêmico" são, assim, os conceitos desenvolvidos pelo italiano que permitiram estender a concepção gramsciana de hegemonia ao sistema interestatal moderno. 
Arrighi também descreve um conflito de lógicas de poder nas disputas hegemônicas, através do embate entre a lógica capitalista e a lógica territorialista. Pela primeira, o território constitui um intermédio para a aquisição de pagamentos adicionais, de fonte de acumulação. Pela segunda, o meio econômico é o intermédio para a conquista territorial. Contudo, ele assinala que a partir da ascensão hegemônica britânica, ocorrerá uma fusão destas duas lógicas, traço característico da dominação estadunidense.

Como os aspectos da ocorrência da acumulação capitalista também eram identificados de forma mais ou menos padronizada, Arrighi alia estes elementos na ocorrência de ciclos hegemônicos, o que constitui os ciclos de acumulação sistêmicos. Ele observa que em cada ciclo há uma primeira fase de expansão material, seguida de outra de expansão financeira. Como explica Moishe Postone:

A financeirização desempenha um papel crucial na sucessão de um hegemon por outro, de acordo com Arrighi. Conforme ele a descreve, a trajetória ascendente de cada hegemon é baseada na expansão da produção e do comércio. Em um ponto de cada ciclo, contudo, uma "crise sinalizadora" ocorre como resultado da sobreacumulação de capital. Outro Estado fornece então um meio para dar vazão a esse capital acumulado. Neste esquema, a crescente financeirização requer a transferência de capital do hegemon atual para um novo hegemon ascendente ${ }^{23}$. Esse padrão de desenvolvimento não é, entretanto, completamente cíclico. Ele tem direcionalidade. Cada novo ciclo é mais curto que o precedente; cada novo hegemon é maior, mais complexo e mais poderoso. Cada hegemon consegue internalizar custos que seu antecessor não internalizava. A Holanda internalizou custos de produção, o Reino Unido também internalizou custos de produção e os Estados Unidos adicionaram a internalização de custos de transação ${ }^{24}$. Estabelecendo este padrão, Arrighi argumenta então que a fase atual de financeirização é sinal do declínio da hegemonia americana, o começo do fim do quarto ciclo. (POSTONE, 2015)

\section{David Harvey e o conceito de Imperialismo}

A definição de "novo" imperialismo tem como fundamental o entendimento da perspectiva histórica que vem sendo desenhada para o capitalismo internacional. Seu ponto de apoio são as definições de imperialismo elaboradas por Lênin e Rosa Luxemburgo, pois:

Por razões muito distintas, e utilizando também argumentos diferentes, consideravam que o imperialismo - uma forma determinada de produção do espaço- era a resposta para o enigma (da sobrevivência do capitalismo), ainda que ambos postulassem que esta solução estava limitada por suas próprias contradições. (HARVEY, 2006, p.95)

Então, ele dará importância central ao conceito de imperialismo para interpretação dos dilemas contemporâneos do capital, em meio às crises recentes. Entende que há uma prática imperialista privilegiada para a transferência das crises para outros territórios. No entanto, 
apesar de admitir que futuros eventos possam, talvez, abrir concretamente a oportunidade de uma nova ascensão hegemônica, sua análise é mais cautelosa no sentido de afirmar que, desde a crise de 1970, estaríamos, na realidade, numa transição do fordismo ao pós-fordismo. Sua preocupação maior está em compreender a dinâmica atual do imperialismo, ao invés de assinalar a dinâmica de um novo ciclo hegemônico.

O primeiro entendimento de imperialismo, enquanto fenômeno,refere-se à observação, nos países capitalistas avançados do final do século XIX e início do século XX, de um descompasso entre a acumulação de capital, somada a altas taxas de investimento, e a impossibilidade dos capitalistas aumentarem as taxas de exploração da força de trabalho nos seus respectivos países. As taxas de lucro declinavam, levando à exportação de capitais para áreas não-capitalistas para obtenção de um rendimento mais elevado, expandindo o mercado.

No seu denso estudo sobre o imperialismo, Lenin (1987) se apoia na definição de Hilferding do capital financeiro oriundo da fusão entre capital bancário e capital industrial para analisar a dinâmica imperialista. Como as principais decisões a respeito das operações comerciais e industriais ocorriam junto aos grandes bancos, observou-se um aumento considerável da concentração de capitais, o que, para Lenin, marcava a tendência à monopolização da economia.

Considerando o aumento da composição orgânica do capital nos principais países capitalistas, o capital financeiro busca áreas novas com uma baixa composição orgânica de capital, mão de obra abundante e possibilidades novas de expansão financeira. A dominação imperialista eleva, então, a coerção sobre o trabalho. Estes são os principais traços do parasitismo imperialista, inerente ao capitalismo, segundo Lenin (1987).

Rosa Luxemburgo aponta as contradições na reprodução ampliada do capital, o que leva os capitalistas a "se associarem ao seu Estado para, mediante esta aliança, poderem disputar militarmente o controle sobre as zonas onde ainda não dominam as relações especificamente capitalistas de produção"(MARIUTTI, 2013, p.28). A reprodução ampliada recorre, para "desafogar" as crises, ao expediente da acumulação primitiva.

Harvey (2006), como dissemos, desenvolve a ideia de "novo imperialismo" através da acumulação por espoliação. Ele considera que a teoria geral da acumulação de capital de Marx tem supostos iniciais que, em termos gerais, coincidem com a Economia Política clássica: mercados competitivos que funcionam livremente segundo as normas burguesas ao redor do ordenamento jurídico, garantia da propriedade privada, e estruturas legais e 
governamentais que atuam como "facilitadores" da atividade econômica. Nesta situação, a acumulação "primitiva" ou "originária" já ocorreu, e ela se desenvolve enquanto reprodução ampliada do capital dentro de uma economia fechada "que opera em condições de 'paz, propriedade e igualdade" (HARVEY, 2006, p.108). Ele enfatiza que o método de Marx mostra que a liberalização mercantil, seja pelo projeto da economia política clássica, seja pelo projeto neoliberal, não produzirá um estado de harmonia no qual todos ganham, mas, pelo contrário, assistir-se-á (como de fato assistimos) a um crescente nível de desigualdade social, culminando nas crises de sobreacumulação contemporâneas.

O problema nessas "premissas comuns" é que a acumulação enquanto atividade predatória, opressora, de rapina, não ocupa espaço relevante. Harvey considera fundamental um novo olhar sobre a permanência e persistências destas práticas, já como traços característicos (e não "exteriores") do capitalismo. Como ele vê esse processo ainda em curso, denomina-o como "acumulação por espoliação", e guarda as principais características do entendimento marxista sobre imperialismo:

Como ressaltaram Lênin, Hilferding e Luxemburgo, o sistema de crédito e o capital financeiro foram fatores que influíram significativamente na depreciação, na fraude e no roubo. As promoções bursáteis, os esquemas de ponzi, a destruição estruturada de ativos através da inflação, o esvaziamento através de fusões e aquisições, a promoção de níveis de endividamento que mesmo nos países capitalistas avançados reduzem populações inteiras à servidão por dívidas, para não mencionar a fraude corporativa, a espoliação de ativos (o ataque dos fundos de pensão e sua liquidação pelos colapsos acionários e corporativos) mediante a manipulação de crédito e ações, todos são traços centrais do que é o capitalismo contemporâneo. (HARVEY, 2006, p.109-110)

O geógrafo vai além e assinala que a acumulação por espoliação se utiliza de novos mecanismos para atuar em praticamente todas as esferas da sociedade. Encontra-se essa expressão na política neoliberal de retorno ao domínio privado de direitos de propriedade comum ligados às questões de bem-estar social, de privatização e pilhagem dos recursos ambientais, genéticos, das formas culturais, dos ativos públicos (como universidades e instituições de ensino), dos bens comuns em geral.

Harvey identifica, pela sua perspectiva teórica, um padrão de fases históricas que relaciona a ascensão do imperialismo com o domínio capitalista global. Ainda que formações capitalistas anteriores tivessem um centro hegemônico que se utilizava de "práticas quaseimperialistas que buscam ajustes espaço-temporais para seus problemas de sobreacumulação" (Ibid., 2006, p.111), ele segue o argumento de Hannah Arendt de que "o imperialismo centrado na Europa durante o período 1884-1945 constituiu a primeira tentativa de domínio político global por parte da burguesia” (Ibid., 2006, p.111). A confirmação do prognóstico de 
Lenin acerca das disputas inter-imperialistas levou a segunda fase deste domínio global com a ascensão hegemônica dos EUA em 1945 através de uma aliança global (via acordos de Bretton-Woods) para evitar os problemas da sobreacumulação da década de 1930. Para Harvey:

Esta segunda fase do domínio global burguês foi possível em grande medida pela contingência da guerra fria. Esta pressupunha a liderança militar e econômica estadunidense como o único superpoder capitalista. $\mathrm{O}$ efeito foi a construção de um "superimperialismo" estadunidense hegemônico, que era mais político e militar que uma manifestação de necessidade econômica. (Ibid, 2006, p.112)

A crise econômica dos anos 1970 quebra essa segunda fase, a Guerra do Vietnã e a crise do petróleo leva ao desgaste da liderança dos EUA e a uma reorientação na condução hegemônica sucessivamente. É sobre esse período em diante que se colocam as principais diferenças entre Arrighi e Harvey, as quais observaremos a seguir.

\section{Arrighi contestado}

Harvey vê o capital financeiro como central para o que seria a terceira fase do domínio global burguês. A ofensiva financeira estadunidense ocorre por estarem ameaçados no terreno da produção. Novos acordos financeiro-institucionais são firmados na arena internacional, tendo sido o FMI intermediário privilegiado para arranjar o compromisso neoliberal dos países com a economia mundial.

A financeirização é um traço assinalado por Arrighi, como vimos, que marca o início da decadência hegemônica. Ao constatar sua ocorrência, Harvey preocupa-se em analisar se o prognóstico apontado pelo outro pode ter ocorrido:

Se, por exemplo, Braudel (seguido por Arrighi) está no caminho certo, e uma poderosa onda de "financeirização" pode ser o prelúdio de uma transferência do poder dominante de um hegemônico a outro, a virada dos EUA no sentido da "financeirização" nos anos 70 parecia exemplificar um padrão histórico de autodestruição. (Ibid., 2006, p.115)

Ele segue argumentando que a capacidade dos EUA de explorar o domínio financeiro internacional permitiu-os de evitar o que outros países se viram obrigados a fazer. Diz Postone que:

O tratamento de Harvey da financeirização, entretanto, é menos centrado no Estado do que o de Arrighi, o qual é ligado à questão dos hegemons ascendentes e declinantes. De fato, Harvey enfatiza que, no mundo contemporâneo, o capital não tem locus ou posição determinada, mas é difuso e global. (POSTONE, 2015)

Os agentes capitalistas, então, seguiram avançando na acumulação por espoliação, ainda que a economia estadunidense se tornou macroeconomicamente distorcida e instável. Seus sucessivos governantes têm lidado praticamente com os mesmos problemas econômicos 
de outrora. São contradições presentes na dinâmica do quarto ciclo hegemônico, segundo o esquema do italiano:

Embora ele (Arrighi) caracterize o ciclo americano como anômalo, ele não explica o seu caráter anômalo. Por conseguinte, existe uma lacuna entre sua interpretação eclética da década de 1970 e sua estrutura teórica mais ampla, o que sugere que o padrão de desenvolvimento que ele delineia é essencialmente descritivo. Ele não apresenta, de fato, uma análise acerca do que move o padrão de desenvolvimento que ele descreve. Ibid, 2015)

Uma característica anômala, apontada por Arrighi acerca do fim do quarto ciclo, é que essa transição estaria ocorrendo sem a escalada de conflitos que marcou a transição dos ciclos anteriores. Ainda que seu esquema fique fragilizado, a dinâmica de uma possível ascensão pacífica da China tem mostrado mais indícios até o presente momento. Assinala que a economia chinesa substituiu os EUA como a economia que mais cresce no mundo, tendo configurado como a principal beneficiária da globalização projetado pelos próprios EUA, buscando uma ascensão que não perturbe a ordem existente (ARRIGHI, 2008).

Harvey, mesmo sendo crítico ao esquema do italiano, assume que este está certo em dizer que uma configuração única se deu a partir da crise de 1973, e não descarta que grandes mudanças geopolíticas possam ocorrer no cenário internacional, sendo bem mais cauteloso em afirmar perspectivas mais certeiras em relação ao "novo imperialismo".

\section{Harvey contestado}

Por outro lado, o italiano também tece uma série de críticas ao pensamento do geógrafo. Num debate franco, utiliza uma definição de imperialismo diferente da versão leninista-luxemburguista. Para ele:

O significado mais geral é extensão ou imposição do poder, autoridade ou influência de um Estado sobre outros Estados ou comunidades sem Estado. Compreendido isso, o imperialismo está por aí há muito tempo sob formas muito variadas. (ARRIGHI, 2008, p.221)

Ainda assim, ele se dispõe a debater com Harvey sobre o sentido geral do imperialismo "do tipo capitalista", o qual o geógrafo entende (coerentemente com o que já apontamos acima sobre o seu pensamento) como fusão contraditória entre "a política do Estado e do império" e "os processos moleculares de acumulação do capital no espaço e no tempo" (HARVEY, 2004, p.32). Arrighi direciona a discussão para a compreensão da gênese dos EUA como potência supermilitarizada com um ambicioso projeto de domínio mundial.

$\mathrm{Na}$ sequência, o italiano debate a respeito do conceito de "acumulação por 


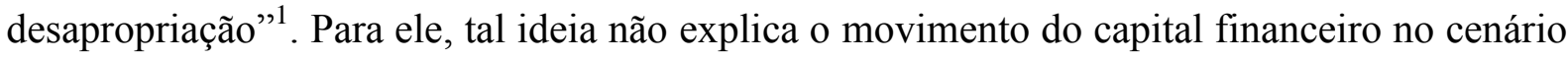
internacional, principalmente o fato dos Estados Unidos mais terem tomado emprestado (chegando ao ritmo de 2 bilhões de dólares por dia) do que emprestaram, propriamente dito. Também não explicaria uma perspectiva política de maior escalada militar estadunidense apontada por Harvey, que teria sido uma tendência verificada pela ofensiva militar no Iraque promovida por George W. Bush.

Entretanto, com o fracasso grosseiro do militarismo de Bush, o próprio Harvey assume a contingência dessa ofensiva, e Arrighi aponta essa contradição no seu esquema, argumentando que a arena global estaria menos propícia a embates desse tipo naquele momento. Ainda sobre o esquema de Harvey:

Para identificar toda a gama de possibilidades históricas propostas pelo desenrolar da hegemonia norte-americana, os conceitos de ajuste espacial e de acumulação por desapropriação devem ser reconfigurados de um ponto de vista histórico mais amplo e extenso do que o de Harvey. Dentro dessa óptica, o novo imperialismo surgirá como resultado, de um lado, de um longo processo histórico de tamanho e alcance cada vez maiores e, de outro, das tentativas dos Estados Unidos de levar esse processo a cabo por meio da formação de um governo mundial centrado neles próprios. Essa tentativa, afirmo eu, fazia parte da hegemonia norte-americana desde o princípio. (ARRIGHI, 2008, p.237)

Reforçando a importância da investigação histórica para a compreensão dos fenômenos sócio-econômicos, Arrighi diz que Harvey é vago sobre qual o lugar histórico que ocupou o capital financeiro como mediador na produção de espaço envolvida na reprodução ampliada do capital, e defende que embora isso seja certo em relação ao desenvolvimento capitalista de alguns Estados, não é verdadeiro no caso deste desenvolvimento em escala mundial. Ele defende que toda análise histórica feita por Braudel é consistente para fornecer as ferramentas teóricas necessárias à sua teoria dos ciclos hegemônicos, e mostra os aspectos dessa investigação na sua obra (ARRIGHI, 2008).

\section{Considerações finais}

O estudo da discussão entre os dois autores que fizemos é mais uma mostra da importância de analisar a forma como são construídas as argumentações e como conclusões inovadoras podem ser extraídas de um processo como esse.

Vimos como ambos partem de definições distintas e procuraram ser coerentes de acordo com a metodologia e a posição teórica que assumiram. Ao invés de debaterem

\footnotetext{
${ }^{1}$ A expressão original de Harvey, em inglês, é "Accumulation by Dispossession”. Houve uma divergência entre a tradução da obra de HARVEY (2006) e ARRIGHI (2008). Optamos por manter o termo traduzido conforme a edição, mas entendendo que se trata do mesmo conceito.
} 
superficialmente, apegando-se exclusivamente aos fatos mais contemporâneos, entenderam ser necessário questionar os pressupostos do outro no debate.

Em vários momentos, entretanto, pudemos ver que partilham de certos entendimentos que se evidenciaram ao longo da discussão. Por exemplo, ambos parecem concordar que o imperialismo deve ser considerado "o primeiro estágio do domínio político da burguesia, em vez de último estágio do capitalismo" (ARRIGHI, 2008, p.244). Mas é divergente da ideia de Lenin de estágio final do capitalismo.

Também concordam a respeito de um aspecto que auxilia o entendimento de como a hegemonia estadunidense tem perdurado sem a ocorrência de sublevações internas que pudessem estabilizar a liderança global dos EUA. Como a sociedade burguesa é incapaz de resolver os problemas internos de desigualdade e instabilidade sociais, recorre-se a buscar soluções externas, por meio do comércio exterior e práticas coloniais/imperiais. Contudo, o incentivo a uma feroz individualidade de uma população multicultural separada por várias barreiras étnicas invisíveis, combinada com a propagação ideológica a respeito do temor permanente a paz e segurança interna constantemente ameaçadas pelos "outros", os "agentes externos", tudo isso serve como bússola moral para guiar firmemente uma sociedade civil que pareceu sair totalmente do controle em muitas oportunidades.

Demonstramos essas posições convergentes para ilustrar como segue a discussão, principalmente a respeito das perspectivas sobre mudanças na dominação hegemônicaimperialista. $\mathrm{O}$ arcabouço teórico fornecido ainda tem servido para que autores marxistas continuem analisando a dinâmica atual e confirmando ou negando prognósticos estabelecidos anteriormente. Os acontecimentos mais recentes certamente trarão novos desafios para os que acompanham a dinâmica histórica do capitalismo contemporâneo, talvez oferecendo momentos de transições históricas de grandes proporções. 


\section{Referências Bibliográficas}

ALVES, Ana Rodrigues Cavalcanti. O Conceito de Hegemonia: de Gramsci a Laclau e Mouffe. São Paulo: Lua Nova, 2010

ANDERSON, P. Considerações sobre o marxismo ocidental. Porto: Edições Afrontamento, 1976.

ARENDT, Hannah. Origens do totalitarismo. São Paulo: Companhia das Letras, 2004.

ARRIGHI, Giovani. Adam Smith em Pequim: origens e fundamentos do século XXI. São Paulo: Boitempo Editorial, 2008.

. O Longo Século XX. Rio de Janeiro: Contraponto, 2013.

FRANCO, Thiago Fernandes. Imperialismo capitalista em três atos: investigações sobre o capitalismo. Campinas: IE/UNICAMP, 2011.

HARVEY, David. O enigma do capital e as crises do capitalismo. São Paulo: Boitempo Editorial, 2011.

O novo imperialismo. Trad. São Paulo: Loyola, 2004.

“O novo" imperialismo: acumulação por espoliação in: Socialist

Register 2004, O novo desafio imperial. São Paulo: CLACSO, 2006

LENIN, Vladimir I. O Estado e a Revolução. São Paulo: Expressão Popular, 2007.

O imperialismo: fase superior do capitalismo. São Paulo: Global, 1987.

LUXEMBURG, Rosa. A acumulação de capital: contribuição ao estudo econômico do imperialismo. São Paulo: Abril Cultural, 1984

MARIUTTI, Eduardo B. Interpretações clássicas do imperialismo. Campinas: IE/UNICAMP, 2013.

POSTONE, Moshe. Teorizando o mundo contemporâneo. David Harvey, Giovanni Arrighi e Robert Brenner. Disponível em: $<$ https://blogdaboitempo.com.br/2015/06/06/postone-teorizando-o-mundo-contemporaneodavid-harvey-giovanni-arrighi-e-robert-brenner/> Acesso em 02 de Maio de 2017. 